\title{
Sistemas alimentarios y patrimonio alimentario. Transculturaciones en el caso ecuatoriano*
}

Catalina Unigarro**

\begin{abstract}
RESUMEN

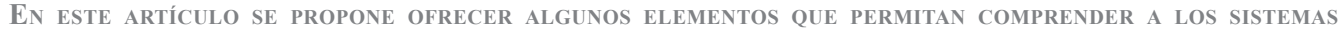
ALIMENTARIOS COMO PATRIMONIO, Y AL PATRIMONiO ALIMENTARIO COMO RESUltado DE HISTÓRICOS PROCESOS de transculturación. Para desarrollar nuestro objetivo, abordaremos en primera instancia, NOCIONES QUE NOS AYUDEN A ENTENDER QUÉ TIPO DE SABERES Y PRÁCTICAS CONFIGURAN UNA COCINA, ENTENDIDA ésta como sistema alimentario. Seguidamente, Se asumirán a dichas prácticas como parte de un Fenómeno de patrimonialización. Finalmente, Se PResentarán Algunos hitos históricos Que describen BREVEMENTE LA EVOLUCIÓN DEL SISTEMA ALIMENTARIO, QUE EN EL CASO ECUATORIANO EVIDENCIA PROCESOS DE TRANSCULTURACIÓN.
\end{abstract}

Palabras Clave: sistema alimentario - cocina - Patrimonio alimentario - transculturación alimentaria.

\section{Abstract}

THIS ARTICle AIMS TO OFFER ELEMENTS THAT ALLOW UNDERSTANDING FOOD SYSTEMS AS HERITAGE, AND FOOD HERITAGE AS A RESULT OF HISTORICAL PROCESSES OF TRANSCULTURATION. IN ORDER TO DEVELOP OUR OBJECTIVE, WE WILL ADDRESS IN THE FIRST INSTANCE, NOTIONS WHICH HELP US TO UNDERSTAND WHAT KIND OF KNOWLEDGE AND PRACTICES SET UP A KITCHEN, UNDERSTOOD AS FOOD SYSTEM. IN ADDITION THESE PRACTICES ARE ASSUMED TO BE A PART OF THERE PROCESS OF BECOMING HERITAge. FINALly, WE WILl PRESENT SOME HISTORICAL LANDMARKS THAT BRIEFLY DESCRIBE THE EVOLUTION OF THE FOOD SYSTEM, WHICH IN THE CASE OF ECUADOR DEMONSTRATES PROCESSES OF TRANSCULTURATION.

KEYWORDS: COOKING - FOOD SYSTEM - FOOD CULTURE - FOOD HERITAGE - FOOD TRANSCULTURATION.

* Este artículo recoge algunas de las reflexiones desarrolladas en mis trabajos de investigación sobre el tema alimentario, principalmente, las presentadas en la investigación "De la Chacra al Fogón. Travesía por las rutas de la papa, el maíz, el plátano y la yuca” y más recientemente, en la experiencia del "Atlas Alimentario de Pichincha” (inédito)

** Magister en Estudios de la Cultura, Universidad Andina Simón Bolívar. Investigadora. 


\title{
La cocina: un sistema cultural alimentario
}

T a alimentación es una experiencia que se encuentra articulada a diferentes dimensiones de la actividad humana, y ello puede confrontarse con la amplia variedad de ciencias y perspectivas que se han utilizado para su estudio. Reconocemos que en el hecho alimentario se vinculan factores de diversa naturaleza (ecológicos, biológicos, médicos, económicos, ideológicos y socio-culturales) que se interrelacionan entre sí, siendo necesario acudir a esta multiplicidad de miradas para acercarnos a su comprensión.

Consideramos el hecho alimentario como una de las actividades humanas que permite de mejor manera desentrañar aspectos de los más variados órdenes de la estructura social en la que se produce. "Es, en el sentido dado por Mauss (1950), un hecho social total, entendiendo que todas las áreas de la cultura y tipos de instituciones (económicas, jurídicas, políticas, religiosas, etc.) encuentran en él expresiones simultáneas y le influyen de algún modo" (Contreras y Gracia, 2005: 15).

Apelando al enfoque del materialismo cultural, Fischler (1995) comprende a la alimentación como un fenómeno en el que se expresa el hombre biológico y el social de manera integrada. Y es que comemos no sólo porque nuestro cuerpo biológico necesita de alimento, sino también, porque existen condicionamientos de tipo cultural que modelan esta necesidad natural. Dicho de otro modo, lo que comemos no se reduce a la satisfacción de una necesidad de hambre ni a un asunto de salud o nutrición. La alimentación es en su sentido amplio una representación de la cultura que revela una concepción particular del mundo, en el que dos universos, naturaleza y cultura, se implican. Lo que de otro lado supone que los sistemas alimentarios serán tan variados como sistemas culturales existan, pues las elecciones alimentarias dependen de dichos sistemas. Desde ésta perspectiva, las cocinas varían en función de sus entornos particulares, gozan de una especificidad, por lo que no pueden ser estudiadas como experiencias universales.

\begin{abstract}
"Existen, en efecto, muchas clases de indicios que muestran que los humanos eligen sus alimentos, en buena parte, en función de sistemas culturales alimentarios que pueden llamarse cocinas. La analogía entre lenguaje y cocina, trivial desde Lévi-Strauss, se impone aquí: todos los humanos hablan una lengua, pero existe un gran número de lenguas diferentes; todos los humanos comen una comida cocida, pero existe un gran número de cocinas diferentes. La cocina es universal; las cocinas son diversas" (Ibíd.: 33-34).
\end{abstract}

En el sentido dado por Fischler, la cocina es un sistema alimentario que no se reduce a los ingredientes y las formas de preparación de alimentos, sentido usualmente más utilizado. La definición planteada por el autor, permite situar de manera apropiada la coexistencia de una multiplicidad de prácticas que permiten redimensionar su significado:

\footnotetext{
"Se puede entender $<<$ cocina $>>$ en un sentido diferente, más amplio y más específico a la vez: representaciones, creencias y prácticas que están asociadas a ella y que comparten los individuos que forman parte de una cultura o de un grupo en el interior de esta cultura. Cada cultura posee una cocina específica que implica clasificaciones, taxonomías particulares y un conjunto complejo de reglas que atienden no sólo a la preparación y combinación de alimentos, sino también a su cosecha y a su consumo. Posee igualmente significaciones que están en dependencia estrecha de la manera como se aplican las reglas culinarias" (Ibíd.: 34).
}

Considerando una perspectiva biocultural -que contempla las implicaciones biológicas y sociales de las prácticas culturales-, Armelagos (2003) propone una organización de estos conocimientos y prácticas de la cocina como sistema alimentario, en cuatro componentes. Y son: i) los alimentos que se seleccionan del medio, ii) la forma de prepararlos, iii) las reglas sobre el comer y iv) el principio del sabor. Se trata de principios comunes a cualquier cocina pero que se expresan de manera distinta en cada contexto, por lo que como cualquier 
otro aspecto de la cultura, deben examinarse dentro de la estructura social en la que se reproducen.

i) Alimentos que se seleccionan del medio: Considerando la disponibilidad de alimentos y condiciones de acceso, identificamos aquí al patrimonio natural, esencial para dar inicio a los sistemas alimentarios. Se incluyen los productos en sí como las frutas, granos, legumbres, tubérculos, raíces, especias, aromáticas, ganado, aves, algunos animales de monte, pescados, entre otros; así como sus formas de obtención, saberes asociados a la actividad ganadera, agrícola, de pesca, crianza, recolección y caza.

ii) Formas de prepararlos: En respuesta a una necesidad de variabilidad, las técnicas de preparación surgen para hacer comestible lo que no lo es ${ }^{1}$, y para asegurar su diversificación, permitiendo que el mismo alimento pueda ser consumido de distintas maneras. Se ubican aquí las combinaciones de alimentos y los procedimientos o técnicas de transformación y conservación aplicadas como la cocción en agua, vapor, el uso de aceites, el asoleado, fermentado o ahumado, entre muchos otros. Asimismo, se incluye la creación de utensilios apropiados para su transformación (según cada método de cocción), instrumentos que evolucionan según las necesidades y posibilidades de cada cocina.

iii) Reglas sobre el comer: El consumo de alimentos no sólo supone un valor material dado por sus características nutricionales y organolépticas, le corresponde también valores simbólicos que responden a la manera en la que está organizada la estructura social del grupo que las reproduce. Del cumplimiento de estas pautas puede advertirse relaciones de poder, jerarquizaciones y concepciones en torno a los alimentos (tabúes, propiedades medicinales), consumos según épocas determinadas (festivas, religiosas), así como relaciones de respeto, agradecimiento, prestigio o reciprocidad.

iv) Principio del sabor: Este principio se refiere a aquellas combinaciones particulares de especias y alimentos que, gracias a su uso reiterado, le confieren a la cocina una cualidad particular, una etiqueta familiar, aquella característica que le permite a una cocina distinguirse de otra e identificarse con una cultura específica. Será entonces la condimentación característica, su sabor distintivo, su sazón.

En ese orden de ideas, la cocina comprende un conjunto de prácticas de producción y obtención de alimentos, como aquellas referidas a su transformación y consumo, es decir, prácticas culturales agrícolas y culinarias, y los sistemas simbólicos asociados a ellas. Estos elementos permiten formular una consideración inicial referida a que el patrimonio alimentario de un país no está referido a la enunciación de "platos nacionales", sino a un universo que implica al sistema alimentario en su amplitud: productos animales y vegetales, formas de obtención (siembra, recolección, crianza, caza, pesca), formas de preparación, espacios y tiempos de consumo, saberes y concepciones asociados a ellos, usos medicinales, tabúes, entre otros.

\section{Patrimonio alimentario}

Se han planteado hasta el momento elementos para dimensionar las prácticas y saberes que comprenden las cocinas, vistas como sistemas alimentarios; pensemos ahora en dichas prácticas como expresiones de un universo patrimonial. Zapata (2008: 153) nos aproxima a dicha noción definiendo la patrimonialización como "[...] la interiorización colectiva de valores

1 Lévi-Strauss (1972) explica este fenómeno de transformación del alimento a través de su tesis estructuralista del triángulo culinario: crudo-cocido-podrido. En esta relación, la preparación de los alimentos expresa un desplazamiento de un estado natural a uno cultural, resultado de una intervención humana que supone un ejercicio de pensamiento en el que se consideran variados aspectos como la temperatura, el tiempo, la relación del agua y el fuego, el desarrollo de artefactos apropiados, entre otros. 
culturales (gustativos, sociales, históricos, geográficos) con los cuales se construye el patrimonio gastronómico"?.

$\mathrm{Si}$ asumimos cocina como un sistema alimentario complejo en el que intervienen una diversidad de actores, espacios y procesos, proponemos considerar el patrimonio alimentario como el conjunto de saberes y conocimientos, así como las prácticas agrícolas y culinarias que han experimentado una interiorización colectiva, una apropiación simbólica y material que es transmitida de generación en generación, que se recrea en la cotidianidad de un grupo social y que se consolida como referente de identidad, permitiendo establecer vínculos con un territorio. Apelamos a la referencia que sobre cocinas nacionales recogen Contreras y Gracia (2005), para insistir en el valor patrimonial dado a determinadas prácticas alimentarias.

"Diferentes autores (Fieldhouse, 1986:54; Back, 1977:32) consideran que una cocina nacional es aquella que refiere, fundamentalmente, a aquellos alimentos y modos de prepararlos que son considerados como normales, propios o específicos de un determinado país y que, en esa misma medida, constituye un aspecto de su identidad como grupo. Precisamente, porque es la «(norma» no es considerada como una expresión de individualidad o de afirmación individual, sino, más bien, como un aspecto de la identidad grupal. Al igual que otros rasgos sociales o pautas culturales, la cocina nacional es considerada, por los miembros de dicha comunidad, como algo dado, que está ahí y que requiere de pocas explicaciones más, pues sólo las desviaciones de la «(norma» son percibidas como tales" (Contreras y Gracia, 2005: 204). ${ }^{3}$

Es justamente este atributo extendido, la coincidencia sobre su valor material y simbólico, lo que le confiere a un sistema alimentario el carácter patrimonial, valor que tiene que ver con su participación en la configuración de la memoria, historia e identidad de un país. Dichos conocimientos se fundan en saberes ancestrales ${ }^{4}$ que dialogan con fenómenos contemporáneos, pues al igual que la identidad, el patrimonio es una manifestación que se actualiza. Se funda en el pasado, pero se recrea y reproduce en el presente.

Este valor patrimonial no se reconoce en cualquier conocimiento o práctica relacionada al alimento. Éste cobra sentido en aquellos sistemas alimentarios que han evolucionado al interior de cada cultura según sus necesidades de experimentación y adaptación; son reconocidos localmente como importantes símbolos de la memoria e identidad de los pueblos, resultando "adecuados en términos productivos nutricionales, y culturales" (Carrera, 2014: 9).

\section{Transculturación alimentaria}

Los sistemas alimentarios evolucionan con las culturas y estas lo hacen por variados motivos. Hay algunos conocimientos o prácticas en dichos sistemas que son más o menos estables, como el uso extendido de la papa o el uso medicinal atribuido a algunas hierbas aromáticas, y otros, como el uso del fogón, o la apropiación del verde, que cambian debido a razones económicas, políticas, ecológicas, culturales. Muchas de estas transformaciones han ocurrido gracias a intercambios alimentarios dados en distintos momentos de la historia, y es ahí donde encontraremos la afirmación de las raíces y algunas de las adaptaciones más importantes del patrimonio alimentario ecuatoriano.

2 El autor considera a la gastronomía como un "patrimonio intangible y expresión cualitativa alimentaria de un país o región, [que] comprende juicios de valor con universalidad de criterios estético-gustativos" (Zapata, 2008: 153). La gastronomía y/o culinaria son asumidas aquí como cocinas.

3 El reconocimiento de un patrimonio alimentario de ninguna manera se agota con la identificación de platos nacionales. En la cita del autor, la mención a una cocina nacional permite centrar la atención en aquellos elementos del sistema alimentario de un país que tienen carácter patrimonial.

4 Se utiliza el concepto ancestral en lugar de tradicional por considerase el más adecuado. Lo ancestral se asume como aquello que tiene una fuerza milenaria y que remite a los conocimientos y saberes de los pueblos originarios. Lo tradicional en cambio, refiere a una práctica cuya frecuencia de uso la dota de dicha característica, por lo que es necesario su vínculo a una raíz, a un territorio. En ese sentido y para lograr un entendimiento más apropiado del patrimonio alimentario, se utilizará la noción de ancestralidad. 
Para comprender las transformaciones ocurridas en las cocinas del país resultado del encuentro entre culturas 5 , apelamos a la categoría de transculturación formulada por Fernando Ortiz (2002) en tanto resulta más apropiada que la de mestizaje. Esta última, de uso generalizado, sugiere una connotación biológica que acentúa, en la comprensión del encuentro, el hecho de la "mezcla" entre poblaciones de orígenes étnicos diversos, proponiendo, más que una comprensión del fenómeno cultural, un acercamiento al hecho "racial".

En el encuentro/desencuentro de culturas, existen procesos de selección que se activan en el mismo momento en que el individuo se enfrenta a elementos ajenos a su cultura propia. Es ahí cuando resuelve apropiarse o no de los mismos, según sus propios códigos culturales y resignificarlos, transformarlos, recrearlos e incorporarlos en sus propias prácticas como estrategia de resistencia. Desde esta perspectiva, el contacto no supone por sí mismo, el sometimiento de una cultura por parte de otra. No se trata de fenómenos de pérdida absoluta, ni con vocación de integridad. Por el contrario, cuando dos culturas se encuentran, ocurre una afectación que en mayor o menor medida transforma mutuamente a los dos universos implicados.

\begin{abstract}
"Entendemos que el vocablo transculturación expresa mejor las diferentes fases del proceso transitivo de una cultura a otra, porque éste no consiste solamente en adquirir una distinta cultura, que es lo que en rigor indica la voz angloamericana acculturation, sino que el proceso implica también necesariamente la pérdida o desarraigo de una cultura precedente, lo que pudiera decirse una parcial desculturación, y, además, significa la consiguiente creación de nuevos fenómenos culturales que pudieran denominarse de neoculturación. Al fin, como bien sostiene la escuela de Malinowski, en todo abrazo de culturas sucede lo que en la cópula genética de los individuos: la criatura siempre tiene algo de ambos progenitores, pero también siempre es distinta de cada uno de los dos ${ }^{6}$. En conjunto, el proceso es una transculturación, y este vocablo comprende todas las fases de su parábola”. (Ibíd.: 260).
\end{abstract}

En el contacto de dos culturas ocurre un intercambio, que innegablemente está definido por relaciones de poder en el que probablemente una de las partes resulta dominante. Sin embargo, no supone la eliminación de una de las culturas y la superposición de otra, sino una experiencia de alquimia, en el que nuevos códigos culturales que eventualmente llegan a apropiarse, en todo o en parte, dan lugar a una nueva realidad para ambas culturas. Este planteamiento, es clave para comprender los intercambios alimentarios y es en este sentido, de recíproca influencia, que se entenderán aquí dichas apropiaciones. Por tales motivos, consideramos al patrimonio alimentario del país como un sistema alimentario transculturado.

\title{
Transculturaciones en el patrimonio alimentario ecuatoriano
}

Las culturas alimentarias se enfrentan a intercambios de manera permanente. Algunos suceden de manera lenta, obedeciendo a procesos de adaptación ecológica y cultural y, otros, son asimilados con mayor facilidad, quizá por ser complementarios o afines a las prácticas locales. De cualquier modo, una vez incorporados, aquellos elementos nuevos logran arraigarse de manera profunda, tomando el lugar de lo propio, volviéndose familiar.

Podríamos apuntar que estas transculturaciones han ocurrido de igual manera en la región, dada la similitud de procesos históricos de conformación de territorio, de organización política y dada la afinidad de zonas ecológicas que la conforman. La configuración de los sistemas culturales alimentarios responde a condicionamientos de cada momento histórico, respondiendo a intereses de un heterogéneo grupo de actores. Desarrollamos a continuación, una breve mención

5 Encuentro que por supuesto no se agota con el primerísimo intercambio ocurrido con la conquista sino que se nutre de fenómenos culturales y recomposiciones locales contemporáneas. Dados los similares procesos históricos en la región, el proceso de transculturación alimentaria que aquí describo, podría revelarnos una realidad análoga a la de países vecinos.

6 Se refiere a la escuela funcionalista de antropología (nota de Enrico Mario Santí). 
de algunos hitos históricos que podrían dar pistas para comprender la aparición del patrimonio alimentario en Ecuador ${ }^{7}$, que como se verá es resultado de un rico proceso de adaptación y resignificación, testimonio de la reinvención y creatividad de los actores.

En las raíces del patrimonio alimentario, ubicamos algunos alimentos prehispánicos de origen animal y vegetal, que son transversales a varias de las prácticas alimentarias actuales, lo que evidencia la pervivencia de su filiación indígena. En la alimentación andina predominaba el consumo de maíz, calabaza y fréjol, triada alimentaria primordial para los primeros pobladores de la región americana. Se definía por el consumo de animales pequeños, por lo general silvestres, y la domesticación de pocas especies animales, siendo la llama la de mayor tamaño y no apta para ser utilizada en labores de arado, por lo que los pueblos americanos contaban con el desarrollo de técnicas agrícolas que casi no dependían de la fuerza y estiércol de animales domésticos (Crosby: 2003), lo que les llevó a desarrollar distintas técnicas y herramientas para el trabajo de la tierra.

Gracias a evidencias arqueológicas, se sostiene que en Ecuador "es muy probable que la agricultura se inició en la región de la costa y posteriormente la tecnología se difundió hacia la región interandina, en donde los hallazgos más remotos de alimentos cultivados corresponden a una época de aproximadamente 2.000 años antes de la era cristiana" (Naranjo, 1991: 112). Estrella, por su parte, precisa que ésta inicia en "Las vegas, en la península de Santa Elena, hace más de 8.000 años" (Estrella, 1998: 33).

Estrella identifica en la agricultura prehispánica la existencia de diferentes técnicas de cultivo resultado de la variabilidad ecológica propia del Ecuador. Entre ellas, el cultivo en tierras de aluvión (utilización de terrenos luego de épocas de invierno); en camellones (tierras inundables con diseño de canales de cultivos alternos); en tierras secas, cultivo de riego, andenes y terrazas (principalmente en zonas secas como la Costa); de roza y quema (en los meses de verano, antes de la siembra); barbecho (dejar de sembrar durante uno o varios ciclos), además de la técnica de cultivos asociados (que por otra parte representa un modelo de fertilización natural de la tierra) (Estrella, 1998).

Esta agricultura prehispánica se inscribió en el marco de un macrosistema de intercambios que desde épocas remotas permitieron asegurar una variabilidad en las cocinas de pueblos social y étnicamente diferentes. Estas prácticas obedecieron a un fenómeno de islas o archipiélagos ecológicos que según, el estudio de Murra (2002), se dio aún desde épocas preincaicas, y estuvo referido a la producción, circulación y consumo de recursos entre territorios ecológicamente diversos -zonas altas, medias y bajas-, lo que permitió a los primeros pobladores del área andina tener acceso a alimentos variados, posibilitando así una autosuficiencia económica y una variabilidad alimentaria. Sostiene el autor: "mi inclinación es considerar los archipiélagos como un método antiguo, elaborado por sucesivas poblaciones andinas para la mejor percepción y utilización de los recursos en su extraordinario conjunto de ambientes geográficos" (Murra, 2002: 121-122).

Este sistema explicaría un rasgo de la agricultura andina antes de la conquista incaica y española, y es la no dependencia del ciclo estacional, lo que sugeriría el acceso a un conjunto de recursos durante todo el año sin las limitaciones impuestas por el clima. Sin embargo, las transformaciones en las estructuras socio-económicas y políticas luego de las conquistas, hicieron volver a la dependencia de un ciclo agrario. Esta circulación de productos entre diversas zonas fue posible gracias a las condiciones ecológicas del Ecuador caracterizadas por una amplia biodiversidad en regiones cercanas entre sí, lo que hizo posible la adopción de alimentos variados, bien como resultado de donaciones, trueques, intercambio de excedentes, o el traslado de pobladores a zonas vecinas de ecosistemas diferentes, en las que era posible la producción de otros recursos (Estrella, 1998; Camacho, 2006; Pazos B., 2008).

7 Los datos que aquí presentamos hacen parte de los resultados obtenidos en la investigación etnográfica realizada sobre cuatro alimentos emblemáticos de las cocinas del país: maíz, papa, plátano, yuca. No se trató de un estudio exhaustivo, pero ofrece significativas claves para acercarse a la comprensión del sistema alimentario de Ecuador. 
A esta agricultura y disponibilidad variada de alimentos, debemos sumarle las técnicas culinarias desarrolladas para su preparación, técnicas que suponen la consecuente elaboración de utensilios apropiados para su realización como tiestos, piedras, cedazos, pondos, ralladores; el uso de elementos de la naturaleza fundamentales para su transformación, como el agua, fuego, humo y el uso de las hojas de algunos árboles. En ellos encontramos varias técnicas comunes a las cocinas de hoy, lo que evidencia su larga tradición. Basándose en fuentes arqueológicas y antropológicas, Pazos (2005) identifica las siguientes técnicas prehispánicas:

\footnotetext{
"Tostaron el maíz, lo molieron en metales, asaron tortillas en tiestos y piedras lajas, cernieron en cedazos, sancocharon, asolearon carnes, ahumaron carnes, asaron carnes a la brasa, maceraron la chicha en pondos, cocinaron en agua los tubérculos, majaron tubérculos, sancocharon, envolvieron en hojas los tubérculos, aliñaron los alimentos, rallaron los tubérculos, y masticaron el maíz para acelerar la fermentación" (Ibíd.: 370).
}

El método de cocción a base de agua es una técnica ancestral común a las cocinas del mundo y quizá la más utilizada en las cocinas del país. Moler o majar los alimentos también es una técnica bastante antigua utilizada en una variedad de preparaciones, sobre todo para la elaboración de harinas y para la obtención de masas de diverso tipo. Se cuenta con la técnica de maceración para la elaboración de la chicha y también es posible encontrar en comunidades amazónicas la técnica de la masticación de la yuca para facilitar su fermentación, utilizada en la preparación de la chicha. El rallado es común a todos los alimentos, aplicado en su mayoría para procesarlos en su estado crudo.

De igual manera variaciones en técnica de asado, destacándose el uso del tostado de granos principalmente, y el asado en tiesto de barro, propio de la elaboración de tortillas de maíz y del casabe o pan de yuca. La cocción de alimentos con la utilización de hojas como envoltura, se encuentra en varias preparaciones emblemáticas de las cocinas del país como el maito o ayampaco de yuca, propio del oriente ecuatoriano, que se obtiene envolviendo carne de pescado (o de otros animales) en hojas de bijao o platanillo, tamales y bollos de verde o maduro y el ayampaco de verde, etcétera.

Complementariamente, se contaba con varias técnicas de conservación de alimentos que facilitarían "su almacenamiento, transporte y utilización" (Estrella, 1998: 36). Entre las que Estrella (1998) identifica están el asoleo, salado-asoleo, cocción-asoleo, cocción-remojadoasoleo, putrefacción-asoleo, salado-asoleo, cocción-remojado-asoleo, putrefacción-asoleo, salado-ahumado, congelación-remojo-asoleo, maceración-asoleo, tostado-molido.

Además de estos procedimientos y utensilios, sobrevive en la actualidad un rasgo de la cocina indígena prehispánica y es la textura espesa de sus elaboraciones culinarias. Acudiendo al análisis de Roberto Ramia, Pazos afirma:

"Se nota el predominio de las texturas espesas, aspecto que según Roberto Ramia, autor del análisis del recetario de Doloritas Gangotena, el siglo XIX, se debe a los productos de la cocina inca: papa, maíz, oca, mashua, melloco, yuca, arracacha, achira, fréjol, porotón, todos ricos en féculas" (Pazos, 2006: 2).

Aunque Pazos indica que la presencia de esta textura se debe a la utilización de alimentos ricos en carbohidratos propios de la cocina inca, considerando la procedencia de algunos de los alimentos mencionados, podría tratarse de un rasgo anterior a la invasión incaria. Sin embargo, es bastante probable que su uso se haya generalizado o intensificado como consecuencia de dicho acontecimiento.

El posterior contacto colonial, supuso una época de intensos cambios. El proceso de colonización incidió en la configuración de una estructura jerárquica que ordenó las relaciones sociales en razón a la pertenencia étnica y el acceso a los medios de producción, lo que a la vez permitió la atribución de ciertos roles en la sociedad que, poco a poco, fueron naturalizados a 
través del discurso colonizador. Dicha estratificación social supuso una división de trabajo, en la que unos sectores -el indio y el negro- servían a través del trabajo manual a otros, españoles, criollos y mestizos. De acuerdo con la posición ocupada en dicha estructura social, es posible identificar la especificidad de los roles ocupados en la sociedad y, por ende, la manera en la que probablemente se efectuó la interiorización de los alimentos en el patrimonio alimentario del país.

En este momento histórico, sumamente conflictivo y estratificado, se ubica el inicio de una cocina criolla en Ecuador, refiriéndose a aquella cocina resultado de la interacción entre la tradición culinaria negra, indígena y española, es decir, a los conocimientos, saberes y prácticas alimentarias resultado de la convivencia entre culturas diferentes. Las transculturaciones que se pueden ubicar en este momento, son resultado de estrategias de imposición por la institución colonial como fue el caso del trigo, el plátano, el cerdo o las habas, entre otros, que se adaptaron con distintos niveles de aceptación, pero que enriquecieron los sistemas alimentarios propios gracias al contacto de las cocinas indígenas y negras con las cocinas de las familias criollas o españolas, produciéndose una "coexistencia de interacciones y la producción cultural entre miembros de tradiciones culturales radicalmente diferentes" (Sevilla, 2007: 262).

El traslado de especies animales y vegetales representó un esfuerzo del poder colonizador para reproducir en todo o en parte sus propias cocinas, necesidad asociada a la creencia de que las prácticas alimentarias nativas eran culturalmente inferiores. Por tanto, la imposición de algunos alimentos y tecnologías, constituyó un ejercicio de poder sustentado en la validez de sus prácticas en contraposición a la inferioridad de las nativas. Como precisa Albán (2007: 263), "la necesidad de mantener una hegemonía socio-cultural se reflejó igualmente en el intento de hegemonizar la comida por imposición o por traducción a los códigos gastronómicos importados para reemplazar los existentes".

De la herencia hispánica, encontramos algunos recursos introducidos en las cocinas andinas como por ejemplo la "gallina, tao, ganso, vaca, conejo, oveja, chivo, cerdo" (Pazos, 2006: 6), de generalizada producción y consumo en las cocinas de hoy; y vegetales como "el trigo, cebada, arroz, caña de azúcar, col, lechuga, alverja, lenteja, haba, naranja, limón, durazno, higo, mango, mora pimienta, comino, ajo, perejil, culantro, hierba luisa, arrayán, manzana..." (Ibíd.), entre otros. Sobre las técnicas culinarias puede destacarse la introducción de tres técnicas principalmente: hornear, freír y cocer a vapor (Ibíd., 2005). Se produce en definitiva, un flujo de alimentos de origen vegetal y animal, que generó para colonizadores y colonizados, la adopción de algunos alimentos -como los cereales en el caso americano, y alimentos como el maíz y la papa, en el caso europeo-, que han logrado un lugar importante en la dieta alimentaria de los pueblos y se han generalizado a las cocinas de todo el mundo.

Sobre los principales cambios destacamos la adaptación del plátano, siendo uno de los grandes aportes alimentarios para la cocina del Ecuador. Sus orígenes en el mundo se remontan al sudeste asiático (Fernández-Armestro, 2004) desde donde la planta emigró a África y por tanto a las Islas Canarias, el archipiélago español ubicado al norte de ese continente. Más tarde llegaría a América gracias a que fray Tomás de Berlanga la introdujo en la isla comprendida por Haití y República Dominicana, llamada entonces La Española (Acción Ecológica, 2012), y desde ahí se extendería rápidamente a las zonas semi-tropicales de América. En Ecuador se instaló de buena manera en la zona costera y oriental de la Amazonía, convirtiéndose en un alimento fundamental de sus cocinas.

El plátano se ha consolidado como el gran protagonista de las cocinas costeñas y amazónicas; sin él sería difícil o imposible imaginar las delicias de sus cocinas. Esta cualidad cultural del alimento aunado a los beneficios que ha representado para la economía del país hace de él un alimento excepcional. Sin duda, ha llegado a interiorizarse tan profundamente en las identidades del país que hoy es tan propio como cualquier alimento americano. 
Además destacamos la introducción del horno de leña ${ }^{8} \mathrm{y}$, por extensión, de todas aquellas técnicas asociadas a su uso, y la paila, de suma importancia en el menaje de las cocinas de hoy; "su importancia se refleja en muchos de los inventarios que acompañan cartas de dote o testamentos, donde este objeto consta como parte del patrimonio familiar" (Sevilla, 2007: 266). Estos dos utensilios no sólo representan el símbolo de una cultura que se impuso sobre la nativa, sino también estrategias de apropiación por parte de los habitantes originarios, quienes combinaron los nuevos artefactos para transformar sabores de alimentos nativos.

La adaptación de animales como la gallina, el cerdo y la vaca hizo que progresivamente se fuera incluyendo la carne en las dietas americanas. Con los animales aparecen además las frituras, en las que se combina el uso de la paila y el aprovechamiento de grasas animales. Y es que el freído, el horneado y el cocido a vapor son técnicas hispanas fundamentales en las prácticas culinarias de hoy. Su importancia se pone en evidencia en la frecuencia de su práctica. La utilización del horno se adaptó bien a preparaciones hechas con alimentos americanos y también fue un artefacto importante en el desarrollo de la panadería.

De la confluencia de alimentos y prácticas es la sopa uno de los aportes más significativos a las conocimientos culinarios del país. Sobre su apropiación, afirma Pazos (1986: 55): “de allá [Europa] vinieron las sopas, de aquí sobrevivieron los sangos", y refiriéndose al locro, el mismo autor apunta: "esta incorporación es europea, porque antes de la llegada de los conquistadores, en la cocina incaica, no existían los caldos o los fondos" (Ibíd., 2010: 35).

Como indicamos, la textura espesa de algunas elaboraciones es una característica de la cocina prehispánica debido a la incorporación mayoritaria de alimentos ricos en féculas, como el maíz y la papa, que le otorgan una textura densa, pastosa. Al parecer, en las prácticas europeas se utilizaba más los fondos o caldos de consistencia más liquida, que entrarían a modificar las preparaciones originarias y darían inicio a las populares sopas. A las cocinas americanas se heredaron las sopas, a las españolas sus posibilidades con alimentos americanos:

“...los platos españoles no solo cambiaron de nombre sino de ingredientes. Así fue como el cocido español se transformó en el sancocho criollo. El registro de las primeras sopas de los conquistadores se refiere a sus ingredientes: hierbas nativas, papas diversas, arracacha, maíz soca (tierno) y algún pájaro cazado a pedradas porque la pólvora era escasa y cara. Esta sopa no es muy diferente de las sopas autóctonas consumidas hoy" (Ramírez y David, 2003: 40).

En las décadas posteriores, y en medio de la reordenación política y social de la naciente República, se consolidó una cocina criolla, resultado de un contradictorio clima social en el que se tomaba consciencia de una identidad con herencias culturales distintas. Paralelamente se extiende una clara influencia francesa e inglesa, a través de las cocinas de las clases dominantes. Este afrancesamiento ocurre primordialmente en la aplicación de normas alimentarias para el comer en la cocina de la alta sociedad quiteña. Según Pazos (2008: 248): “el afrancesamiento se impone; aunque [...] se hace presente la fuerte presencia de una clase media vinculada con su origen indio. Se trata de una modernidad que más tarde se desvanecerá y que dejará paso a la cocina ecuatoriana actual, salvo en los casos de la cocina oficial y de la alta burguesía de origen bancario y empresarial". Al final de este periodo, empieza a destacarse la utilización de alimentos importados y la variación del menaje en las cocinas, principalmente en las ciudades recién fundadas.

La jerarquización de alimentos que encontrábamos tan marcada en los primeros años de la conquista aunque se mantiene a lo largo de la República y en las décadas posteriores, empezó a menguar, pues algunos de los alimentos que tenían una connotación simbólica negativa, como

8 Anterior al horno de leña, existía el horno prehispánico que "fue una vasija de arcilla que se calentaba con la brasa" (Pazos, 2005: 371). Este horno puede encontrarse actualmente en la zona de Manabí. Consiste en una especie de olla de barro con una red metálica en su interior, que puede adaptarse sin problema a las cocinas de gas de hoy. 
el caso de la papa o el plátano, empezaron a figurar en clases más acomodadas, donde se tenía mayor resistencia a su apropiación. Entre las razones que podrían explicar este cambio en las normas alimentarias, Naranjo (2006: 10) identifica "primero, determinar la composición química de los alimentos y segundo, establecer el valor nutricional de los mismos", posibilidades que permitía los inicios de un mundo moderno. Estos cambios permitieron adoptar concepciones diferentes en torno a los alimentos en las que empieza a aparecer la noción de lo natural, nutritivo y saludable.

La industrialización en el país empezó a hacerse evidente hacia fines del siglo XIX, incrementándose en los años posteriores. A inicios del siglo XX, hay un importante crecimiento arquitectónico, industrial y demográfico, sobre todo en las ciudades. Paralelamente se viven las consecuencias del auge cauchero en el oriente, que se extendió entre 1850 y 1920 (Vicuña, 1993), lo que ocasionó el ingreso de empresas extractoras y misiones religiosas (Jesuita principalmente), migración peruana y colombiana y por ende, una transformación de la vida de las comunidades amazónicas. Hacia 1930 en la costa, se enfrentaban las secuelas de la baja del precio en el cacao, lo que desplazó al país de su posición privilegiada de ser el principal exportador. Sin embargo, pronto se verían los beneficios económicos de la incursión en el sector bananero, que llevó a Ecuador a posicionarse entre 1948 y 1955 en el principal productor del mundo. Esta actividad, como algunas otras potencialmente lucrativas, estuvo ligada a la acción de multinacionales establecidas en el país, como la United Fruit Company, que se dedicó a la comercialización del banano. El posterior otorgamiento de concesiones a empresas extranjeras para la extracción de petróleo es otro ejemplo.

Estos cambios en la vida social del país, generaron un incremento del comercio, que se vio favorecido con las vías de transporte, intensificando relaciones capitalistas de producción. Además del desarrollo de actividades económicas, la conectividad entre las regiones propició mayor intercambio entre las poblaciones, como ocurrió en el área de Imbabura con la construcción de la vía panamericana:

\footnotetext{
"Para el caso del Valle del Chota-Mira la carretera Panamericana construida hacia 1970 va a permitir mayor intercambio entre este valle y la frontera con Colombia por un lado, y por otro mayores niveles de comercialización con Ibarra y Quito dándoles una más estrecha conexión que la que había alcanzado con la construcción de la vía férrea. De otra parte la construcción de la vía al mar estableció otra ruta de salida del Valle del Chota-Mira tanto hacia Quito como hacia Esmeraldas en la Costa pacífica ecuatoriana" (Albán, 2007: 388).
}

Esta conexión hizo posible la circulación de otro tipo de bienes y servicios, entre ellos, una nueva oferta alimentaria y utensilios, resultado del auge de la industrialización. Serán los alimentos procesados como la pasta (fideos), harinas, azúcar refinada, enlatados (principalmente atún y sardina), bebidas con edulcorantes artificiales (colas o gaseosas, jugos artificiales), condimentos artificiales (sazonadores), aceites vegetales y utensilios de porcelana (platos, tazas, bandejas, fuentes) plástico (platos, vasos, tazas), vidrio (vasos, jarras) y aluminio (ollas, sartenes, cubiertos), los que empiezan a figurar en las unidades domésticas del siglo XX y a generar transformaciones en los sistemas alimentarios del país.

Esta nueva realidad coincidió con la implementación de la Revolución Verde, que en el caso americano, se extendió rápidamente después de la experiencia en México a fines de los años cincuenta, en donde se experimentó con tecnología aplicada a prácticas agrícolas y con el desarrollo de variedades de trigo altamente productivas. Esta concepción de la agricultura

9 En los años posteriores al contacto colonial, el plátano fue inicialmente considerado alimento fundamental para los esclavos negros (Contreras y Gracia, 2005). Por su parte, el tubérculo de la papa se asumía también como alimento de las clases populares. Al divulgarse una serie de creencias acerca de que su consumo era causa de enfermedad (Crosby, 2003), se le otorgó un aura negativa que se vio reforzada por su cercanía a los indígenas. En adelante estos prejuicios poco a poco se eliminaron y permitieron una revalorización extendida de dichos alimentos. 
ligada al desarrollo de una máxima productividad, respondió a una preocupación por la escasez de alimentos ante el vertiginoso crecimiento demográfico en el mundo, y un problema de hambre que se pensó, se podía resolver con el desarrollo de sistemas alimentarios altamente productivos.

Estas transformaciones en la concepción de la agricultura, propiciaron que la actividad se insertara en dinámicas de mercado, y que empezaran a popularizarse objetivos de rentabilidad, rapidez y productividad. En 1964 se realizó en el país la primera Reforma Agraria, que buscó la redistribución de tierras para campesinos pobres (indígenas y afros -en el valle del ChotaMira) que habían sufrido explotación por el sistema hacendatario anterior, pero mantuvo preferencias para los sectores terratenientes. Algunas comunidades lograron adquirir terrenos de estas haciendas, y se produjo una "minifundización ${ }^{10}$ de la tierra que irá a significar, a medida que avanza el siglo XX, una dificultad para estos pequeños propietarios" (Albán, 2007: 389). Con la Reforma se inició un proceso de tecnificación del sector agropecuario, principalmente en las áreas de productos ligados a la agroindustria (Barril, 1978) y en terrenos de grandes extensiones.

Cambian las formas de producción con la tecnificación e incorporación de químicos sintéticos (pesticidas, fungicidas, fertilizantes), transformando al agro en una actividad dependiente del mercado. Hacia la década del setenta, se inauguró el periodo del boom petrolero con el descubrimiento de pozos comerciales en el oriente ecuatoriano, lo que representaría flujo de dinero, empleo, créditos para el sector agropecuario y para la compra de tierras, subsidios, importación de insumos para el campo (Archetti y Stolen, 1981), entre otros. Con la crisis social y económica de fines de los noventa y la consecuente dolarización de la economía en el 2000 , se incentivará un flujo migratorio interno e internacional importante. Entre otros, muchas familias se fragmentaron ante la ausencia de las cabezas de familia en el hogar, motivada por la misma migración y por la creciente inserción laboral de muchas mujeres, principalmente de origen rural. Se advierte un despoblamiento del campo, así como una complementación de la economía doméstica con los ingresos generados por los migrantes. En definitiva, en el siglo XX, Ecuador experimentó procesos de urbanización, industrialización, migración y tecnificación que ocurren con diferente intensidad en sus provincias, dinámicas de un proceso común a América Latina.

Las últimas décadas, están marcadas por un proceso de globalización de la economía y la cultura que ha provocado un intenso flujo e intercambio de información, bienes, servicios, sentidos, que son muestra de sociedades cada vez más tecnológicas e hiperconectadas. Este rasgo ha implicado una estandarización de los sistemas alimentarios, una pérdida de identidad de los alimentos en respuesta a un modelo cultural más o menos homogéneo, pero a la vez, y en respuesta a este nuevo contexto, una importante agencia política en torno al tema alimentario desde diferentes lugares de la sociedad civil, que ha dado lugar a la visibilización de los sistemas alimentarios como expresiones del patrimonio. Estamos frente a iniciativas que se vienen impulsando décadas atrás, de manera autónoma, que no necesariamente se expresan en términos patrimoniales y que han permitido revalorizar los sistemas alimentarios propios.

10 Éste es un rasgo importante que repercute en las transformaciones de las cocinas, y se encuentra ligado al problema de tenencia de tierra que no ha podido ser resuelto de forma equitativa con las reformas agrarias implementadas. Además de la concentración de propiedad de grandes extensiones y de la falta de tierras de calidad por el empobrecimiento biológico de las mismas (en la costa principalmente), entre los pequeños productores se identifica una disminución de su cantidad (fundamentalmente en la sierra). Según algunos testimonios obtenidos en el 2013, en el marco de una investigación etnográfica sobre alimentos símbolo del Ecuador, en la actualidad, se cuenta con pequeñas porciones de tierra resultado de la venta y división de terrenos por razones de herencia, que ha dado lugar a la existencia de pequeñas porciones de tierra (minifundio). Entre otros aspectos, esta disminución altera las labores agrícolas: disminuyen las posibilidades de diversificación y experimentación de cultivos, de disponibilidad de alimentos y en algunos casos, imposibilita la tenencia y crianza de animales, originando una incapacidad para satisfacer ampliamente las necesidades alimentarias de las familias. Esta concepción sobre la propiedad es por supuesto variable, condicionada por múltiples factores culturales, según las necesidades de cada comunidad, las condiciones ecológicas y la naturaleza de cada alimento, por lo que su realidad no puede asumirse como homogénea. 
Y es que existe un consenso cada vez mayor sobre el valor superior que ostentan estos sistemas alimentarios, caracterizados por la producción y uso de alimentos orgánicos, nativos, variados, obtenidos con procesos amigables y respetuosos del entorno; transformados con prácticas que consideran los conocimientos y saberes ancestrales y contemporáneos (como los que se han mencionado: el uso de hojas para la cocción, fermentación o ahumado de alimentos para su conservación, utilización de adobos y especias naturales, desarrollo de cultivos mixtos), que están orientados por una evolución cultural propia y no así, los que se han incluido obedeciendo a fenómenos productivos que tienden a la estandarización (como la crianza de animales con concentrado, los monocultivos, la súper producción de una única variedad de papa, el uso de adobos sintéticos, el uso de alimentos congelados y cualquier otra manifestación de similares características).

Podemos señalar aquí iniciativas que buscan retornar a los sistemas alimentarios propios como la Red de Guardianes de Semillas a través de sus bancos de semillas nativas; el movimiento internacional SlowFood, las crecientes ferias agroecológicas y mercados locales; el mantenimiento de chacras y huertas domésticas; las experiencias de agricultura urbana; el rescate y mantenimiento de variedades nativas de alimentos; el interés de algunos chefs o cocineros locales de ampliar las posibilidades culinarias de alimentos nativos en las cocinas actuales; la recuperación de sistemas ancestrales de producción de alimentos que se han perdido o están en riesgo de hacerlo, que en definitiva, expresan un interés por reivindicar el sistema alimentario propio por razones de soberanía, calidad nutricional, agro biodiversidad, valor cultural y gustativo, y desde luego, por razones de identidad. Existe una mayor consciencia y valorización de alimentos y productos elaborados que se reconocen como parte vital de la cultura ecuatoriana.

A estas experiencias habría que añadirle dos coyunturas que en el caso ecuatoriano posicionaron el tema alimentario con perspectiva patrimonial. El Instituto Iberoamericano de Patrimonio Natural y Cultural IPANC, que como mandato del Convenio Andrés Bello lo presentó explícitamente como objeto de investigación antropológica ${ }^{11}$ (2010), y la creación en el 2012 del Proyecto Patrimonio Cultural Alimentario, por el Ministerio de Cultura y Patrimonio, iniciativas en las que por primera vez el tema alimentario es tratado como patrimonio cultural del país. En palabras de la gerente del proyecto, éste "busca revalorizar y potenciar esa riqueza culinaria nacional representada tanto en sus productos como en su gastronomía tradicional, por ello se lo considera un recurso estratégico en aporte al fortalecimiento de las identidades" (entrevista a Erika Zárate, 2014).

Es la amenaza a la permanencia de los sistemas alimentarios locales, la que ha propiciado iniciativas para su investigación y valorización por parte de las comunidades y más recientemente, desde acciones gubernamentales. Estas nuevas concepciones sobre los alimentos y los contextos de globalización y tecnologización a los que nos hemos referido inicialmente, han propiciado la emergencia de prácticas de salvaguarda del patrimonio alimentario que se inclinan por los sistemas alimentarios ancestrales.

\section{Aportes al debate}

Formulamos a lo largo de este artículo un breve recorrido del patrimonio alimentario en el Ecuador, que exige considerar sus múltiples raíces como resultado de un fenómeno de transculturación que ha enriquecido al sistema alimentario del país en diversos niveles.

En las cocinas de la actualidad sobreviven saberes milenarios, que evidencian su filiación indígena, y constatan la fuerza histórica con la que se encuentran insertos en las identidades del

11 Los estudios antropológicos en el país se inauguran en los años setenta con la apertura de la Facultad de Ciencias Humanas en la Pontificia Universidad Católica. Previo a estos estudios, que en el tema alimentario se concentraron inicialmente en manifestaciones culturales en torno al maíz, se desarrollaron investigaciones sobre el tema culinario por el Instituto Ecuatoriano del Folklore, hoy CIDAP. (Entrevista a Julio Pazos, 2013). 
país. Se cuenta con adaptaciones agrícolas y culinarias efectuadas por los cambios que produjo la institución colonial (como la apropiación del plátano, la paila, el horno, el cerdo, y la popular sopa, entre muchas otras), así como cambios en las concepciones sobre los alimentos (como las ocurridas en la época de la República con la revalorización y popularización del consumo de papa en otros estratos sociales) que han forjado algunas de los rasgos más representativos de los sistemas alimentarios del país.

Por su parte, los posteriores cambios que trajo la industrialización con la consecuente industria alimentaria y la tecnologización del sector productivo, aunado a intensos y masivos procesos de intercambio - propios de una tendencia globalizadora-, ha permitido en la actualidad, observar con respeto las raíces de este sistema alimentario, y pensar en la necesidad de fortalecer esos rasgos milenarios que lo sostienen. Es así que se piensa a estos sistemas culturales como parte de un patrimonio alimentario que es actualizado, que se reivindica, que busca ser protegido, ante la amenaza de su homogenización y la disolución de su diferencia.

\section{Bibliografía}

Acción Ecológica (Ed.) 2012, "Una mirada al banano transgénico desde la ecología política", en: Alerta Verde. Boletín de Acción Ecológica. Julio 2012. No. 166. Quito: Acción Ecológica. http://www.rallt.org/ PUBLICACIONES/banano\%20GM.pdf (Consultada en mayo de 2015).

Albán, Adolfo. 2007, Tiempos de zango y de guampín: transformaciones gastronómicas, territorialidad y reexistencia socio-cultural en comunidades Afro-descendientes de los valles interandinos del Patía (sur de Colombia) y Chota (norte del Ecuador), siglo XX, Tesis para la obtención del grado de doctor en la Universidad Andina Simón Bolívar, Quito - Ecuador.

Archetti, Eduardo y Stolen, Kristi Anne. 1981, Burguesía rural y campesinado en la sierra ecuatoriana. En Campesinado y estructuras agrarias en América Latina. Quito, CEPLAES.

Armelagos, George. 2003, "Cultura y contacto: el choque de dos cocinas mundiales", en: LONG, J. (Ed.), Conquista y comida. Consecuencias del encuentro de dos mundos. México, Universidad Autónoma de México, pp. 105-129.

Barril García, Alex (Comp.) 1978, "Modernización agropecuaria y economías campesinas”, en: Tecnología agropecuaria y economías campesinas. Quito, CEPLAES.

Camacho, Juana. 2006, "Bueno para comer, bueno para pensar. Comida, cultura y biodiversidad en Cotacachi", en: Rhoades, R. (Ed.) Desarrollo con Identidad. Comunidad, Cultura, y Sustentabilidad en los Andes, Quito, Abya-Yala.

Carrera, Javier; García, Claudia y Unigarro, Catalina. 2014, Atlas del Patrimonio Alimentario de la Provincia de Pichincha, Ministerio de Cultura y Patrimonio, Quito, Inédito.

Contreras, Jesús y Gracia, Mabel. 2005, Alimentación y cultura: perspectivas antropológicas, Barcelona, Ariel.

Crosby, A.W. 2003, "La fusión de dos comidas", en: LONG, J. (Ed.): Conquista y comida. Consecuencias del encuentro de dos mundos. México, Universidad Autónoma de México, pp. 131-144.

Estrella, Eduardo. 1998, El pan de América. Etno-historia de los alimentos aborígenes en el Ecuador, $3^{\mathrm{a}}$ edición [1': 1986], Quito, FUNDACYT.

Fernández-Armesto, Felipe. 2004, Historia de la comida. Alimentos, cocina y civilización, Barcelona, Tusquets Editores, S.A.

Fischler, Claude, 1995, El (h)omnívoro. El gusto, la cocina y el cuerpo, Barcelona, Anagrama, Colección Argumentos.

Harris, Marvin. 1999, Bueno para comer. Enigmas de la alimentación y la cultura, Alianza Editorial.

Levi-Strauss, Claude. 1972, Mitológicas, Fondo de Cultura Económica, México.

Murra, John, V. 2002, El mundo andino. Población, medio ambiente y economía, IEP/Pontifica Universidad Católica del Perú, Lima.

Naranjo, Plutarco. 1991, “Alimentación y nutrición”, en: Geografia de la Salud en el Ecuador, Tomo II. Geografía de la Población Vol. 2, Centro Ecuatoriano de Investigación Geográfica, Quito.

2006, “Cultivos en la salud, nutrición, alimentación y seguridad alimentaria en los países andinos", en: INIAP. Hacia la seguridad y soberania alimentaria de Los Andes, INIAP; PUCE, Quito. 
Ortiz, Fernando. 2002, “Contrapunteo cubano del tabaco y el azúcar”, en: Letras Hispánicas 528, Cátedra, Madrid.

Pazos Barrera, Julio. 2010, "Cocinas regionales andinas", memorias del IV congreso, Corporación editora nacional, Quito.

2008, El sabor de la memoria. Historia de la cocina quiteña. Biblioteca Básica de Quito, 19, FONSAL, Quito.

2005, "La comida criolla, expresión de identidad del Ecuador", en: La participación de la sociedad ecuatoriana en la formación de identidad nacional, Presidencia de la República/CNPCC, Quito.

2006, Mazamorra morada y el patrimonio intangible, IPANC, Quito.

1986, "El viche", en: Difusión Cultural No. 4, Banco Central del Ecuador, Quito.

Pumisacho, Manuel y Sherwood Stephen (Ed.). 2002, "El cultivo de la papa en Ecuador", Quito, Iniap-Cip. En http://es.scribd.com/doc/20552814/24/El-Sistema-de-Wachu-rozado (Consultado en mayo de 2015).

Rama, Ángel. 1987, Transculturación narrativa en América Latina, Siglo Veintiuno editores, México.

Ramírez, Marleni y David, William. 2003, Guía agroculinaria de Cotacachi, Ecuador y sus alrededores, IPGRI - Américas, Cali.

Sevilla Larrea, Carmen. 2007, "La memoria desde el fogón. Espacios y prácticas culinarias como texto y objeto de estudio histórico", en: II Congreso de antropología y arqueología ecuatoriana, Abya-Yala, Quito.

Unigarro, Catalina (et al.). 2014, De la chacra al fogón. Travesía por las rutas de la papa, el plátano, la yuca y el maiz, Ministerio de Cultura y Patrimonio, Quito.

Zárate, Erika. 2014. Entrevista realizada por Alexándra Ávila a Zárate, actual gerente del "Proyecto Patrimonio Cultural Alimentario" para el periódico El Universo. http://www.eluniverso.com/vida-estilo/2014/07/21/ nota/3262211/region-se-identifican-platos

Zapata, S. 2008, "Patrimonialización de la gastronomía peruana y planteamiento de un proyecto de desarrollo", en: Álvarez, M. Y Medina, F.X. (Eds.): Identidades en el plato. El patrimonio cultural alimentario entre Europa y América, Icaria, Barcelona, pp. 153-174.

\section{Páginas web consultadas}

http://redsemillas.org/

https://mishkyhuarmi.wordpress.com/category/slow-food-ecuador/ 